\title{
MATHEMATICAL
}

PROCEEDINGS

(formerly Proceedings)

of the

Cambridge Philosophical Society

VOLUME 78 PART 3

$\mathcal{X}$ ovember 1975

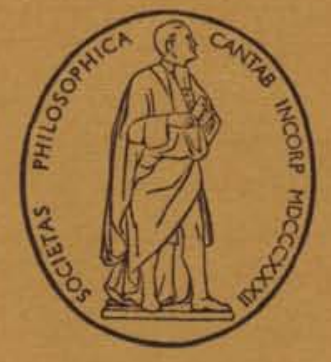

CAMBRIDGE UNIVERSITY PRESS 


\section{CAMBRIDGE PHILOSOPHICAL SOCIETY}

FOUNDED 1819; ROYAI ChaBter 1832

1975

President: DAME HONOR FELL

Vice-Presidents : J. N. AGAR, M. ABERCROMBIE, R. C. EVANS

Treasurer: S. G. FLEET

Secretaries: (Physical) J. E. FIELD

(Biological) M. A. MESSA GE

(Mathematical) A. R. D. MATHIAS

The publications of the Society consist of the Mathematical Proceedings (until 1975 entitled Proceedings) and of the Biological Reviews. The publication of Transactions was suspended at the end of Volume XXIII.

Orders may be sent to any bookseller or subseription agent or direct to Cambridge University Press, P.O. Box 92, London NW1 2DB, or in the U.S.A. and Canada, Cambridge University Press, 32 East 57th Street, New York, N.Y. 10022.

Fellows and Associates of the Society are particularly requested to inform the Secretaries of any change of postal address and to send their subscriptions to the Treasurer, at the Society's office.

Correspondence about library exchanges should be addressed to the Librarian at the Society's office.

Back numbers of Proceedings and Biological Reviews may be obtained from the CAMBRIDGE Philogophioal Socrexy, Bene't Strest, Cambridge, England. All parts of the Proceedings (including the cumulative indices to Vols. 1 to 50,51 to 60 and 61 to 70 ) and of Biological Revieus are available, at prices quoted on inside cover of Volume 77, parts $2,3$.

Information about discounts will also be given. Some parts of Transactions are available from the above addrass. The complete set on microfilm may be obtained from Microfilm Division, E.P. Group of Companies, Bradford Road, East Ardsley, Wakefield, Yorkshire, price 177.

\section{MATHEMATICAL PROCEEDINGS}

$$
\text { of the }
$$

\section{CAMBRIDGE PHILOSOPHICAL SOCIETY edited by}

\section{J. C. BURKILL}

in consultation with
L. E. FRA EN KEL
G. K. EAGLESON
B. BOLLOBAS
R. PENROSE

D. J.H. GARLING

J. E. ROSEBLADE

A. J. MACF ARLANE

H. P. F. SWINNERTON-DYER

\section{J. A. HUDSON \\ C. R. F. MAUNDER \\ A. R. D. MATHIAS}

1. Mathematical Proceedings is published once every two months. Three issues form a volume and two volumes are published each year. The subseription price (which includes postage) of volumes 77 and $78(1975)$ is $£ 12$ net per volume (U.S. $\$ 38.00$ in the U.S.A. and Canada).

2. Scope of the Mathematical Proceedings. Papers which advance knowledge of mathematics, either pure or applied, will be considered by the Editorial Committee. The work must be original and not submitted to another journal. Papers should be sent to the Editor, Mathematical Proceedings, Cambridge Philosophical Society, Bene't Street, Cambridge CB2 3PY, England. Papers in languages other than English should be sent only after prior consultation with the Editor.

3. Correction of proofs. If a paper is accepted, the author will receive in due course page proofs which he is requested to eorrect and return within seven days. To avoid undue disturbance of type, when words or phrases are added in proof, others of equal length should be removed if possible.

If many corrections are made in the proofs, the Council reserve the right to make a charge towards the cost.

4. Authors may receive on request 100 free offprints (for each set of authors in the case of a joint paper). Alternatively authors may have 50 free offprints in covers. Further copies may be obtained at reasonable cost. An order form is inchuded with the proofs of each paper.

5. Suggestions for the preparation of manuseripts are given on the inside back cover of Part 1 .

6. Second class postage paid at Now York, N.Y.

7. (c) Cambridge Philosophical Society, 1975.

For permission to reproduce material from Mathematical Proceedings of the Cambridge Philosophical Society, please apply to the London or New York office of Cambridge University Press.

ISI Tear Service, 325 Chestnut Street, Philadelphia, Pennsylvania 19106, U.S.A. is authorized to supply single copies of separate articles for private use only. 